\title{
DEVELOPING GASTRONOMIC RESOURCES: PRACTICES OF UNESCO CREATIVE CITIES OF GASTRONOMY
}

\author{
Hongrui ZHU \\ Srinakharinwirot University, International College for Sustainability Studies, Bangkok, Thailand, e-mail: hongrui.zhu1988@gmail.com. \\ Mehri YASAMI* \\ Prince of Songkla University, Faculty of Hospitality and Tourism, Kathu, Phuket, Thailand, e-mail: mehri.yasami@yahoo.com
}

\begin{abstract}
Citation: Zhu, H., \& Yasami, M. (2021). DEVELOPING GASTRONOMIC RESOURCES: PRACTICES OF UNESCO CREATIVE CITIES OF GASTRONOMY. GeoJournal of Tourism and Geosites, 39(4spl), 1406-1414. https://doi.org/10.30892/gtg.394spl11-784
\end{abstract}

\begin{abstract}
The category of Cities of Gastronomy has been an integral part of UNESCO Creative Cities Network due to the importance of gastronomic experiences. Against this backdrop, this research aimed to synthesize the gastronomic practices among these member cities and develop a framework based on the synthesis for cities with long-standing gastronomic identities to incorporate gastronomic resources into their long-term planning for gastronomy tourism development. This research adopted thematic analysis to analyze 17 monitoring reports that were submitted by Cities of Gastronomy. The findings identified four key dimensions (infrastructure, attraction, organization, and education) encapsulating 13 subdimensions of developing gastronomic resources among these member cities.
\end{abstract}

Key words: gastronomic resources, gastronomy tourism, food tourism, City of Gastronomy, UNESCO Creative Cities Network

\section{INTRODUCTION}

It has been widely acknowledged that gastronomy is closely associated with tourism (Chaney and Ryan, 2012; Chang and Mak, 2018). Nowadays, gastronomic experiences have become a creative tourism resource for destinations to promote and brand their images (Boyne et al., 2003; Lin et al., 2011) and an influential factor that affects the decision-making process of tourists around the world (Basil and Basil, 2009). In particular, enjoying local cuisines has become one of the significant motivations for tourists to decide where their next holiday destinations will be (Lee and Scott, 2015; UNWTO, 2017). Nowadays, tourists have much easier access to food-related information, including reality shows, review sites, and social media, etc. to help them make such decisions (Park et al., 2019). Moreover, gastronomic experiences, being a core part of travel experiences, have contributed to the overall satisfaction and enjoyment among tourists (Henderson, 2009; Horng and Tsai, 2010). Due to the highly competitive nature of the tourism and hospitality industry, it is of great importance for destinations and cities that have long-standing gastronomic identities to develop, expand, and optimize their existing resources to stand out from the competition and attempt to achieve faster recovery from the impacts exerted by the COVID-19 pandemic. Because of the significant impacts of gastronomic experiences, destinations at national, regional, and local levels have become increasingly aware of the importance of incorporating the development of gastronomic resources into their longterm planning for gastronomy tourism (Karsavuran and Dirlik, 2019). To acclimate such a trend, Cities of Gastronomy, under the framework of the UNESCO Creative Cities Network (UCCN), were awarded to create a platform for member cities to optimize gastronomic resources via local practices and international cooperation and networking (Rosi, 2014).

Although food and food-related experiences have rapidly gained significance within the tourism industry, and account for over 30\% of overall expenditure among tourists (Mak et al., 2012), not all cities with gastronomic traditions and resources have fully turned their strengths into opportunities and revenues (Mohamed et al., 2019). One of the primary goals of UCCN is to fully capitalize on gastronomic potential for creative and sustainable urban development via pioneering ideas and experiences (UCCN, n.d.a). Moreover, many existing studies have focused more on a single destination, region, or city to look into gastronomy tourism (for example, Alimohammadirokni et al., 2021; Karsavuran and Dirlik, 2019; Khoo and Badarulzaman, 2014; Mohamed et al., 2019; Xie, 2021; Y1lmaz et al., 2020); few attempts have been made to synthesize the gastronomic practices undertaken by Cities of Gastronomy within UCCN to develop and optimize gastronomic resources. Against this background, the objectives of this research are to focus on Cities of Gastronomy that have submitted their monitoring report within UCCN, specifically: (1) synthesize the gastronomic practices among Cities of Gastronomy within UCCN, (2) develop a framework based on the synthesis for cities with long-standing gastronomic identities to incorporate gastronomic resources into their long-term planning for gastronomy tourism development.

\section{LITERATURE REVIEW}

UNESCO Creative Cities Network

UCCN, launched in October 2004, is committed to fostering the creative industry sectors and promoting knowledge

\footnotetext{
* Corresponding author
} 
sharing and exchanges among member cities (UCCN, n.d.a). UCCN was created to deal with the fast development of cities and allow each city to find its unique path for cultural diversity and sustainable development through cooperation and interaction (Rosi, 2014). The network covers seven categories, including City of Crafts and Folk Arts, City of Media Arts, City of Film, City of Design, City of Literature, City of Music, and City of Gastronomy. As of 2020, 246 cities from all over the world within the network strive to achieve common missions: developing and promoting creative industry sectors, undertaking creative initiatives at local, regional, national, and international levels, and aiming to strike a balance between creativity and sustainability (UCCN, n.d.a). Cities around the world that are interested in becoming a member of UCCN need to illustrate their willingness in the following aspects: (UCCN, 2016):

- Showcase their cultural assets on a global platform;

- Make creativity an essential element of local economic and social development;

- Share knowledge across cultural clusters around the world;

- Build local capacity and train local cultural actors in business skills;

- Cultivate innovation through the exchange of know-how, experiences, and technological expertise;

- Promote diverse cultural products in national and international markets.

Following the detailed objectives of UCCN (n.d.a), cities within the network are committed to the following practices by engaging with various stakeholders, including the public sector, private sector, and the general public: firstly, they need to actively participate in the creating, producing, distributing and disseminating cultural products and services; secondly, they need to foster a center for creativity and innovation and create more opportunities for cultural professionals; thirdly, they need to promote cultural events to wider audiences so that the whole community, either mainstream or marginalized, can enrich their cultural lives; lastly, they need to strike a balance between cultural creativity and sustainable development. By doing so, these cities not only can upgrade their unique creativity for destination branding on an international stage (Rosi, 2014) but also exert a far-reaching impact on local communities.

\section{Cities of Gastronomy}

As of January 2021, 36 cities around the world have been awarded the title of UNESCO Creative Cities of Gastronomy. Research has suggested that becoming a UNESCO Creative City of Gastronomy is conducive to exchanging knowledge on promoting destinations through gastronomy, enhancing the destination images, and eventually creating economic, cultural, and social values for the local community (Pearson and Pearson, 2017). Before being awarded the title of City of Gastronomy, candidate cities should justify how they meet the following criteria: 1) well-developed gastronomy that is characteristic of the urban center and/or region; 2) vibrant gastronomy community with numerous traditional restaurants and/or chefs; 3) endogenous ingredients used in traditional cooking; 4) local know-how, traditional culinary practices and methods of cooking that have survived industrial/technological advancement; 5) traditional food markets and traditional food industry; 6) tradition of hosting gastronomic festivals, awards, contests and other broadly targeted means of recognition; 7) respect for the environment and promotion of sustainable local products; 8) nurturing of public appreciation, promotion of nutrition in educational institutions and inclusion of biodiversity conservation programs in cooking schools curriculum (UCCN, 2016). After joining the network, each city needs to submit a monitoring report at some point to demonstrate its commitment to gastronomy development at local, regional, and international levels (UCCN, n.d.b). One of the agendas of UCCN is to turn traditional, historical, and cultural resources within destinations into driving forces for creative development (Xiaomin, 2017). Research has revealed that joining UCCN has improved the reputation and popularity of the Cities of Gastronomy (Yllmaz et al., 2020). Thus, UCCN is beneficial for cities that have strong gastronomic identities and resources but lack global fame and popularity to develop and brand their destinations through international networks and cooperation.

\section{Gastronomy Tourism}

Gastronomy tourism refers to the touristic experiences of appreciating and enjoying food-related products in a particular destination (Smith and Xiao, 2008). Food-related experiences not only fulfill the primary needs for the everyday lives of tourists, but also offer a cultural lens to look into local culture and customs while traveling (Sangkaew and Zhu, 2020). Under the combined influences of culture (history, traditions, customs, ethnic people, \& heritages) and the environment (geography \& climate), gastronomic identity can be formed by encapsulating the ingredients, produce, cooking techniques as well as the tastes, flavors, and textures associated with food and beverage of a particular region (Harrington, 2005). Thus, the gastronomy sector has also become an important source of forming cultural identities and destination images (Richards, 2002). Gastronomy has been viewed as a creative and aesthetic cultural product, which is deeply embedded in the urban ambiance and daily lives (Xiaomin, 2017). The creative gastronomic culture can serve as a unique theme for urban development (Nelson, 2015), providing tourists with an important lens of obtaining an insightful understanding of local food culture. Thus, gastronomy tourism serves as one of the appealing and creative sectors that can help a destination to brand itself and attract potential tourists (Kivela and Crotts, 2005; Nelson, 2015), which has developed into one of the vibrant sectors among cities (Mohamed et al., 2019). Nowadays, driven by the changing needs of tourists and homogeneous urban development (Rosi, 2014), local industry practitioners need to innovate local cuisines and modernize gastronomic traditions (Hjalager, 2002). Nowadays, gastronomic creativity and innovation derive from culture, heritage, traditions, and customs inspired by local wisdom and knowledge covering a variety of food-related activities (Xiaomin, 2017).

\section{Developing Gastronomic Resources}

Tourism destinations have become increasingly competitive around the world to attract tourists and generate revenue 
(Khoo and Badarulzaman, 2014; Mohamed et al., 2019) due to rapid changes in technology, disruptive innovation, and globalization (Riza et al., 2012). Although Gastronomic identity was shaped by unique culture, history, and traditions, making it difficult for competitors to imitate (Karsavuran and Dirlik, 2019), it is of great significance for cities to develop a stronger gastronomic identity by optimizing gastronomic resources. The development of gastronomy tourism requires a holistic approach to extend beyond the traditional understanding and perception of consuming local food and appreciating food culture (Karsavuran and Dirlik, 2019), and provide tourists with a combination of a wide range of gastronomic experiences based on local gastronomic culture and traditions. Thus, it is of great significance for destinations to incorporate gastronomy tourism into their long-term planning and optimize gastronomic resources for long-term benefits and advantages (Seyitoğlu and Ivanov, 2020). In terms of the development of gastronomy tourism, Hjalager (2002) explained how to add value to tourists' experiences through a four-order hierarchical typology, which illustrated the complex and sophisticated nature of the gastronomic value chains. Indeed, it illustrates a very holistic way to develop gastronomic tourism at destinations; however, the conceptual typology may be more suitable for destinations to respond to tourist demands, rather than cities with long-term strategic planning for gastronomic tourism (Seyitoğlu and Ivanov, 2020).

Later, Smith and Xiao (2008) formulated a typology of culinary tourism resources that comprises four aspects, including facilities, activities, events, and organizations, for the development of gastronomy tourism. The typology did cover a wide range of aspects for destinations to develop gastronomy tourism but failed to acknowledge tourism education and research as well as professional training as gastronomic resources. Seyitoğlu and Ivanov (2020) proposed a conceptual framework for cities to develop gastronomy tourism through three steps: forming gastronomic identity, developing gastronomic products, and developing strategies to position differentiation. However, the model is more suitable for destinations that have just begun to position gastronomy as a strategic role, rather than cities that have already developed gastronomic identities and tourism products, such as Cities of Gastronomy within UCCN. As mentioned above, Cities of Gastronomy had to meet a series of criteria before being awarded by UCCN, indicating these cities have formed gastronomic identities and developed gastronomic products. However, there has been a paucity of understanding of how these Cities of Gastronomy developed and optimized their gastronomic resources, which can provide references for cities that newly joined UCCN, and cities with gastronomic identities that want to further develop their gastronomic resources.

\section{METHODOLOGY}

This research aims to synthesize the gastronomic practices among these Cities of Gastronomy within UCCN, and develop a framework based on the synthesis for cities with long-standing gastronomic identities to incorporate gastronomic resources into their long-term planning for gastronomy tourism development. To achieve these objectives, this research has utilized the monitoring reports submitted by Cities of Gastronomy for data analysis as these documents provide a holistic perspective of the topics that have been limited studied (Hsieh and Shannon, 2005). As of January 2021, 36 cities around the world have been awarded Cities of Gastronomy within UCCN (see Table 1). UCCN has recently established a four-year period for member cities to submit their monitoring reports, so some early member cities have covered a relatively longer period in their reports and some have not submitted yet. Currently, as seen in Table 1, 18 member cities have submitted their monitoring reports to UCCN. In this research, English is the main language for analyzing the documents and presenting the results, so the monitoring report submitted by Popayán, Colombia, which was written in French, was excluded from this research. Therefore, 17 monitoring reports submitted by Cities of Gastronomy have been collected on UCCN website. Since these reports are available for download online, which pertain to the public domain; therefore, no ethical consideration or approval is required for undertaking the research (Kozinets, 2010). The monitoring report is a document that should be submitted to UCCN by member cities periodically to illustrate what they have committed to the development of gastronomy tourism and share the practices among member cities (UCCN, 2021). The report is normally comprised of six sections, including executive summary, general information, contribution to the program's global management, the initiatives implemented at the local and / or city levels as well as intercity and / or
Table 1. Member cities that have been designated as "Cities of Gastronomy" within UCCN as of January 2021

\begin{tabular}{|l|l|c|c|}
\hline \multicolumn{1}{|c|}{$\begin{array}{c}\text { Cities of } \\
\text { Gastronomy }\end{array}$} & Country & $\begin{array}{c}\text { Year } \\
\text { Designated }\end{array}$ & $\begin{array}{c}\text { Monitoring Report } \\
\text { Period (if submitted) }\end{array}$ \\
\hline Popayán & Colombia & 2005 & $2005-2016$ (in French) \\
\hline Chengdu & China & 2010 & $2010-2017$ \\
\hline Östersund & Sweden & 2010 & $2011-2017$ \\
\hline Jeonju & South Korea & 2012 & $2012-2017$ \\
\hline Zahlé & Lebanon & 2013 & $2013-2017$ \\
\hline Florianópolis & Brazil & 2014 & $2014-2018$ \\
\hline Shunde & China & 2014 & $2014-2018$ \\
\hline Tsuruoka & Japan & 2014 & $2014-2018$ \\
\hline Belém & Brazil & 2015 & $2015-2019$ \\
\hline Bergen & Norway & 2015 & $2015-2019$ \\
\hline Burgos & Spain & 2015 & $2015-2019$ \\
\hline Dénia & Spain & 2015 & $2015-2019$ \\
\hline Ensenada & Mexico & 2015 & $2015-2019$ \\
\hline Gaziantep & Turkey & 2015 & $2015-2019$ \\
\hline Parma & Italy & 2015 & $2015-2019$ \\
\hline Phuket & Thailand & 2015 & $2015-2019$ \\
\hline Rasht & Iran & 2015 & $2015-2019$ \\
\hline Tucson & United States & 2015 & $2015-2019$ \\
\hline Hatay & Turkey & 2015 & Not yet \\
\hline San Antonio & United States & 2015 & Not yet \\
\hline Alba & Italy & 2017 & Not yet \\
\hline Buenaventura & Colombia & 2017 & Not yet \\
\hline Cochabamba & Bolivia & 2017 & Not yet \\
\hline Macao & China & 2017 & Not yet \\
\hline Panama City & Panama & 2017 & Not yet \\
\hline Paraty & Brazil & 2017 & Not yet \\
\hline Afyonkarahisar & Turkey & 2019 & Not yet \\
\hline Arequipa & Peru & 2019 & Not yet \\
\hline Belo Horizonte & Brazil & 2019 & Not yet \\
\hline Bendigo & Australia & 2019 & Not yet \\
\hline Bergamo & Italy & 2019 & Not yet \\
\hline Hyderabad & India & 2019 & Not yet \\
\hline Mérida & Mexico & 2019 & Not yet \\
\hline $\begin{array}{l}\text { Overstrand } \\
\text { Hermanus }\end{array}$ & South Africa & 2019 & Not yet \\
\hline Portoviejo & Ecuador & 2019 & Not yet \\
\hline Yangzhou & China & 2019 & Not yet \\
\hline
\end{tabular}


international cooperation that contribute to achieving UCCN objectives, and proposed action plans for the upcoming reporting period (UCCN, 2021). To address these objectives, this research has focused on the two sections of the monitoring report, which are the gastronomic initiatives at local and intercity levels for analysis. Thematic analysis has been adopted as the method for data analysis, as it has been identified as a frequently adopted and particularly useful method in tourism research to interpret written documents (Walters, 2016).

It allows the researchers to interpret the patterns and themes identified in the data (Braun and Clarke, 2006). Since the synthesis of practices and initiatives of multiple cities has been under-researched, it is exploratory of this research in synthesizing the practices and initiatives undertaken by Cities of Gastronomy. Therefore, a bottom-up inductive approach was adopted to identify themes, which enabled the data to speak for themselves and offered straightforward responses to the research question rather than trying to fit the data into existing frameworks (Braun and Clarke, 2006; Sandelowski, 2000). To capture the initiatives undertaken to develop gastronomic resources, this research focused on the explicit meanings of the data to identify semantic themes and summarize the patterns (Braun and Clarke, 2006).

The thematic analysis involved a series of steps in an iterative and recursive way (Braun and Clarke, 2006). Firstly, the two sections mainly relating to gastronomic initiatives at local and intercity levels in these 17 monitoring reports have been read and re-read to gain familiarity with the content of these documents. Secondly, upon repeated reading, the texts of these two sections were coded for searching basic themes. Following the coding process, basic themes were developed by consolidating all similar codes. In this research, 13 basic themes have been developed, namely, gastronomic facilities, culinary routes, food districts, events, markets, museums, tours, networking within UCCN, local associations, beyond UCCN, academic programs, research, and professional training.

Then, these basic themes were grouped into organizing themes that encapsulated the similarities at a higher level. Four themes (infrastructure, attraction, organization, and education) at an upper level were developed to reflect the homogenous feature. Lastly, these themes were illustrated by selecting compelling excerpts from the empirical materials to display how Cities of Gastronomy developed gastronomy tourism by optimizing local resources and international cooperation. These findings were also discussed with reference to existing literature.

\section{FINDINGS AND DISCUSSION}

\section{Infrastructure}

Infrastructure relating to gastronomy constitutes the backbone of the gastronomic resources within the cities and provides tourists with opportunities to learn about the culinary landscapes and consume local cuisines. These Cities of Gastronomy have established gastronomic facilities, culinary routes, and food districts with creativity to offer impressive experiences to visitors.

Gastronomic Facilities - Cities of Gastronomy understand the importance of providing tourists with unique and memorable gastronomic experiences when they visit the cities; thus it is important to have high-quality gastronomic facilities that incorporate food preparation, processing, demonstration, and consumption. Bergen, for instance, has allowed certain public places to showcase gastronomy: As part of an urban transformation project, the Food Park was established, enabling pop-ups, free cooking courses, and a range of food and creativity related activities for all citizens, including pop-ups from other UNESCO Creative Cities of Gastronomy.

Culinary Routes - Culinary routes and trails are other examples of gastronomic infrastructure that cities can optimize gastronomic resources by working with neighboring regions, including food routes, wine routes, and gourmet trails. Different cities have adopted different strategies to promote these culinary routes. Burgos created thirteen culinary routes to synthesize local gastronomic facilities and resources across the region, including wineries, farms, bakeries, and cheese factories. A brewery trail consisting of nice breweries of the Greater Florianópolis area was designed to provide visitors with sensational and unforgettable memories via artisan beers and gastronomic events.

Food Districts - Creating food-themed districts allows cities to optimize the use of limited space and offer a concentrated zone for tourists to personally taste local specialties and delights as well as understand local cuisine culture. For instance, Gaziantep established a pistachio park where local Gaziantep cuisines are served with locally produced ingredients. By working closely with local stakeholders, including industry practitioners, universities, and scholars, Jeonju developed a unified management system for high-quality ingredients and turned the Hanok Village into a Model Restaurant District with 36 restaurants.

\section{Attraction}

Another important aspect of developing gastronomic resources is to offer diversified gastronomic attractions, which play an essential role in attracting potential tourists. These attractions allow tourists to involve themselves in gastronomic experiences, including acquiring culinary knowledge, sampling local specialties, and touring within the cities or regions, etc. The most popular gastronomic attractions developed by Cities of Gastronomy encapsulate events, markets, museums, and tours.

Events - Gastronomic events are the most popular initiatives undertaken by Cities of Gastronomy in different ways, such as food festivals, food expos, cooking shows, etc., as hosting gastronomic events can attract a large crowd of culinary tourists to the destination within a specific period and increase the visibility of the destination via media exposure and social media. Cities of Gastronomy not only hosted annual gastronomic festivals but also participated in similar festivals hosted by other cities. For instance, Rasht hosts a Pumpkin Festival each year to showcase the localized pumpkins that were originally from all around the world and the creative dishes made from these pumpkins. Belém launched the 
Gastronomic Circuits to promote traditions and "encourage new local food scenes" by creating a platform connecting local stakeholders with tourists: The Gastronomy Circuits include the participation of renowned local and national chefs as well as new talents, also promoting regional cuisine through the boieiras and their traditional street fare.

Markets - Local markets offer a place for tourists to taste food and cuisines, enjoy shopping, as well as appreciate unique local culture and ambiance (Hsieh and Chang, 2006). It is worth noting that the Women Handcraft Market (also called Gil Banoo Project) launched in Rasht, which not only promoted the gastronomic heritage of the city but also empowered women to make economic contributions to the family and society:

Gil Banoo project is a handcraft market with intention of job-creating for women especially female-headed families in the area. [...] Gil Banoo project provides local products of Guilan and especially Rash which is the representation of its folk and cultural identity. Such activities not only recover folk and historic identity but also it helps women to have earning and in this way, the economic condition of bread winner women will be flourishing.

Museums - Museums are another representation of iconic gastronomic attractions within the cities, showcasing local culture, history, heritage, and cuisines. Cities could turn museums into a unique gastronomic attraction by featuring a particular type of locally famous food or produce, such as pistachio in Gaziantep. The world's first museum dedicated to pistachio was opened by Gaziantep Metropolitan Municipality to inform its visitors about the cultivation and use of pistachio in Gaziantep's cuisine. The pistachio shaped museum building can be visited to learn about and to observe different types of products made of pistachio. In the museum, the story of Pistachio is told with moving sculptures made of wax depicted in the traditional and natural pistachio collecting environment.

Tours - Taking a gastronomic tour within the city is another way to grasp a comprehensive understanding of local gastronomic culture. Many Cities of Gastronomy offer creative urban tours targeting tourists. For instance, supported by its longstanding history and gastronomic wealth, and sponsored by governments at different levels, Gaziantep became the starting point of the Gastroway Mesopotamia Tour. Similarly, building up the award-winning cheese, Bergen designed a wine and cheese tour to connect with the Bergen Food Festival where "a range of restaurants invited people of Bergen to participate in a 'wine and cheese walk', choosing to follow one of three different routes".

\section{Organization}

UCCN is one of the most important organizations that facilitate gastronomic development. Cities of Gastronomy have not only worked together in different programs but also cooperated with different creative fields within UCCN. Meanwhile, many cities have cooperated with local associations to issue their food classification system and establish the standard within the region. Moreover, these cities have also participated in organizations beyond UCCN to maximize their gastronomic potential.

Networking within UCCN - On one hand, Cities of Gastronomy have enjoyed the networking and promotional activities in the gastronomic sector. For example, cities like Gaziantep, Tsuruoka, Östersund, Jeonju, and Chengdu among others have taken part in the History of Food Culture-based relations on the Silk Road Project whose purpose is to reinforce cooperation among cities along the Silk Road. To achieve sustainability, it is important to start from the small but common things in daily lives. With regard to food and eating, one obvious aspect is about the leftovers. To tackle this issue, Parma, working with Tucson, launched an initiative of Doggy Bag and encouraged the Cities of Gastronomy to adopt easy anti-waste measures and achieve the mission of "great taste and zero waste". On the other hand, Cities of Gastronomy have collaborated with other creative categories within UCCN. For example, Östersund participated in International Design Manufacturing for Young Designers organized by Shenzhen, City of Design within UCCN. Moreover, Cities of Gastronomy, including Bergen, Dénia, Gaziantep, Tucson, etc., together with other creative cities within the network, participated in the Days of Bread Project, illustrating the important roles bread plays in our daily lives.

Local Associations - Local associations also play a critical role in establishing gastronomy-related regulations and certifications, and promoting particular cuisines and/or destinations to a wider audience. Thus, it is also significant for cities to establish a close relationship with local associations. For example, by cooperating with local associations like the Chamber of Commerce, Chamber of Industry, etc., Gaziantep has created a system of geographical indicators to protect and promote unique local products. More than 40 local products have been registered under the Gaziantep geographical indicator (Karsavuran and Dirlik, 2019). Similarly, Phuket has worked with local government agencies to establish two systems: food hygiene standards for certifying food vendors and Phuket Gastronomy Standard for local restaurants and signature dishes that meet the criteria.

Beyond UCCN - Cities of Gastronomy have also participated in other organizations beyond UCCN to further enhance their visibility on the international market and use the networking effect to promote their destinations, such as the Delice Network, Culinary Heritage Network, and Erasmus+ projects initiated by the European Union. For instance, Gaziantep is not only a member city within UCCN, but also joined Delice Network and Culinary Heritage Network to market their gastronomic heritage and products through a series of professional and international networking. Furthermore, Cities of Gastronomy in Europe, such as Bergen, Dénia, Parma, Östersund, and Gaziantep, have taken part in Erasmus+ projects launched by the European Union like Youth4Food and TastingSchool Union to promote sustainable gastronomic development and encourage youth mobility within the European Union.

\section{Education}

Cities of Gastronomy not only created activities to cater to the needs and interests of tourists from the consumption 
perspective but also attached great significance to academic and professional programs to lay the foundation for qualified graduates, researchers, practitioners, and workforce in the gastronomic sector.

Academic Programs - Some member cities have incorporated academic programs into urban gastronomic development, aiming at fostering interests among young people and cultivating young students in gastronomy. For instance, The University of Alicante (UA) not only offers a Master's Degree in Rice and Applied Mediterranean Haute Cuisine and Undergraduate Degree in Gastronomy and Culinary Arts, but also works with local stakeholders in Dénia to launch the UA-Dénia Mediterranean Gastronomic Center. It aims to become a hub for research teams, employers in the sector and other interest groups, and also to gather resources and tools to boost knowledge, development and innovation in food sciences and culinary arts, as well as excellence in scientific research and technological development.

Research - Many cities have worked with local universities to undertake extensive research on creative and sustainable gastronomy tourism. For example, Östersund collaborated closely with Mid-Sweden University to study how culture, creativity, and gastronomy add value to the development of cities. Also, the Gastronomic Observatory was launched among partner institutions in Florianópolis, aiming to gain an in-depth understanding of the gastronomic sector through research. The Faculty of Agriculture at Yamagata University in Tsuruoka has studied indigenous crops and seeds to understand the local cuisine and traditional cultivation techniques.

Professional Training - Member cities have attached great importance to gastronomic personnel since joining UCCN, including vulnerable and marginalized groups in the society, by providing professional training courses, seminars, and workshops. Cities like Jeonju and Tsuruoka have offered training courses and sessions for cuisine experts, cooks, and servers. Also, other cities, such as Zahlé, Phuket, Burgos, Dénia, Shunde, and Gaziantep, have organized professional training courses targeting vulnerable and marginalized groups, including youth, seniors, women, people with disabilities, unemployed people, etc., to ensure that they have equal opportunities to equip themselves with new knowledge and skills and stronger empowerment to play their roles in the society and support their family.

\section{DISCUSSION}

This research is concerned with the synthesis of the gastronomic practices among these Cities of Gastronomy within UCCN and develop a framework based on the synthesis for cities with long-standing gastronomic identities to incorporate gastronomic resources into their long-term planning for gastronomy tourism development. The dimensions identified from the thematic analysis offer theoretical insights into developing and optimizing gastronomic resources when compared to the extant literature. This research identified four dimensions - infrastructure, attraction, organization, and education - that Cities of Gastronomy adopted to develop their gastronomic resources, which is different from the typology of culinary tourism resources that encompasses four aspects-facilities, activities, events, and organizations (Smith and Xiao, 2008). Specifically speaking, the attraction dimension identified in this research encapsulates a variety of places and occasions where culinary tourists can have an opportunity to be personally involved in the gastronomic experiences, which incorporates some aspects of facilities, activities, and events. More importantly, the typology by Smith and Xiao (2008) failed to acknowledge human resources as one of the core elements of culinary tourism resources for long-term planning. Nowadays, it is of great necessity to acknowledge the significant roles played by qualified human resources, including graduates, researchers, and professionals, to provide memorable gastronomic experiences and plan the development of local gastronomic tourism.

Hjalager (2002) put forward a hierarchical typology of culinary resources which involves four stages of development, including indigenous, horizontal, vertical, and diagonal, but Seyitoğlu and Ivanov (2020) pointed out this typology was not suitable for cities that aim to incorporate gastronomic tourism into their long-term tourism development planning. In this case, Cities of Gastronomy within UCCN already have very well-known gastronomic heritages and histories as well as the initial development of gastronomy tourism initiatives assessed by other member cities when they applied to join UCCN. Also, member cities of UCCN are required to make clear action plans for the next four years by introducing a wide portfolio of gastronomic initiatives for their long-term development. Thus, these member cities did not follow the four stages set out by Hjalager (2002) but developed their gastronomic resources based on their cultural heritages and local specialties.

Rosi (2014) argued that although there were a series of initiatives, such as exhibitions, seminars, workshops, developed and undertaken by Cities of Gastronomy at local levels, the involvement and participation from other member cities were limited. Indeed, it is difficult for other member cities to participate in some local gastronomic initiatives, such as infrastructure. However, the findings have suggested that many member cities have optimized the networking effect and strengthened their alliance by becoming more involved in local initiatives of member cities, including gastronomic events, educational programs, etc. The findings also indicate that the level of engagement and cooperation among these member cities has been strengthened as the network continues to develop. Xiaomin (2017) argued the threshold criteria of a City of Gastronomy only showcased what these cities may look like, but failed to demonstrate how to develop their culinary resources. However, the findings have offered insightful understandings of how these Cities of Gastronomy have developed their gastronomic resources through various initiatives during their first review period. Also, Xiaomin (2017, p. 63) summarized four common characteristics of the first eight Cities of Gastronomy within UCCN, including Popayán, Chengdu, Shunde, Östersund, Jeonju, Zahlé, Florianópolis, and Tsuruoka:

- Cuisine, tourism, and festivals are common features that constitute "City of Gastronomy";

- Sustainability remains a central vision for "City of Gastronomy";

- The extension of creative value chain becomes a new frontier for "City of Gastronomy" 
- Fostering cultural creativity in "City of Gastronomy" through a network of educational institutions and initiatives.

Sustainability and creativity were further supported by the practices done by Cities of Gastronomy. Indeed, Cities of Gastronomy have undertaken numerous sustainable initiatives, striving to contribute to the Sustainable Development Goals adopted by all United Nations Member States. However, the other two characteristics failed to capture the holistic pictures of these Cities of Gastronomy. Firstly, the common features that constitute these member cities also include gastronomic heritage, facilities, and publications among other dimensions that as shown in the findings, rather than just cuisine, tourism, and festivals. Secondly, fostering cultural creativity in these member cities was embedded in many aspects and beyond the network of educational institutions, such as how to creatively use public space to promote gastronomy, how to reduce food waste in creative ways, how to work with creative cities in other fields, like literature, design, etc. within and beyond UCCN, and so on. The member cities that have submitted their monitoring reports have already illustrated a great deal of potential in fostering creativity in developing their gastronomic resources.

Drawing from the findings, this research proposes a framework for cities that have rich gastronomic identities to develop their gastronomic resources as their long-term planning for gastronomy tourism development. The framework incorporates two levels: local level and intercity level. At the local level, cities need to make sure the infrastructure is sufficient enough to support the development of gastronomic attractions. The framework is consistent with the argument that infrastructure is significant for developing food tourism (Mohamed et al., 2019). Also, cities need to provide various platforms for all stakeholders, including researchers, educators, local stakeholders, and industry practitioners, to collaborate based on their actual needs. For instance, cities could fund various research projects to generate practical outputs for local gastronomy tourism to recover from the pandemic.

Or cities could work with educators and local associations to provide supplementary training for those professional industry practitioners who lost their jobs during the pandemic. At the intercity level, the framework encompasses cooperation through networking, knowledge and expertise sharing, and education and research collaboration. The framework highlights the important roles played by cooperation and networking through UCCN or other types of regional or international networks. For cities that have newly joined UCCN, it is of great importance to make the most of the benefits and advantages offered by the network. Cities with gastronomic identities that want to further develop their gastronomic resources could consider joining UCCN or other gastronomic networks to further enhance their gastronomic identity, increase their visibility, and optimize their gastronomic resources through cooperation, networking, and sharing. Moreover, the framework acknowledges the importance of sharing knowledge, expertise, personnel training, education, and research outputs at the intercity level for cities to learn the best practices from each other, which extends the scope of culinary tourism resources (Smith and Xiao, 2008).

\section{CONCLUSION}

By undertaking the thematic analysis, this research synthesized the gastronomic practices among these Cities of Gastronomy who have submitted their monitoring reports and identified four key dimensions (infrastructure, attraction, organization, and education) encapsulating 13 exemplary practices (gastronomic facilities, culinary routes, food districts, events, markets, museums, tours, networking within UCCN, local associations, beyond UCCN, academic programs, research, professional training) among these cities for

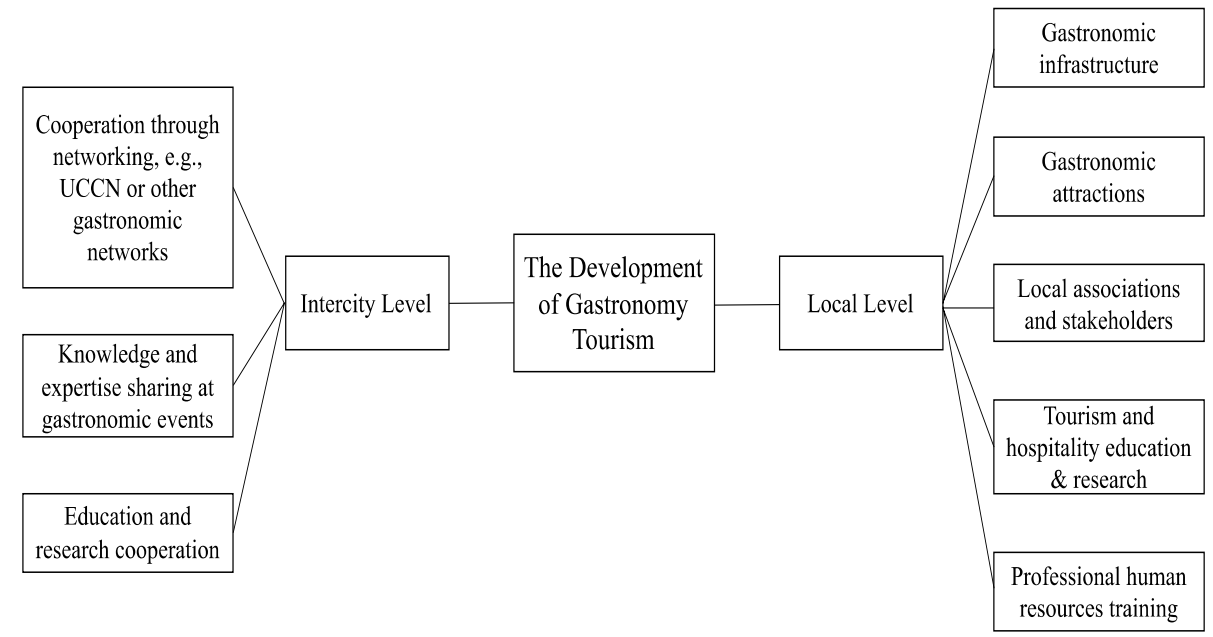

Figure 1. The framework for cities with gastronomic identities to develop their gastronomic resources (Source: Developed by Authors)

developing gastronomic resources. The findings indicated that these member cities have undertaken a wide range of gastronomic initiatives at local and intercity levels to develop and capitalize on their gastronomic resources, which provides examples and references for cities that have long-standing gastronomic identities to develop their gastronomic resources. The research also highlighted that joining international gastronomic networks, such as UCCN, provides advantages for member cities to facilitate further cooperation and networking. This research is one of the first that provided a synthesis of the gastronomic practices and initiatives undertaken by multiple Cities of Gastronomy within UCCN to develop their gastronomic resources and promote their gastronomic identities. The findings of this research contributed new insights regarding the typology of gastronomy tourism, which challenged the previously defined typologies of culinary tourism (Hjalager, 2002; Smith and Xiao, 2008). Another important contribution of this research is to provide a framework (see Figure 1) that encompasses two levels and a range of key dimensions for developing and optimizing gastronomy tourism as their long-term goals for cities with gastronomic identities. The proposed framework goes beyond the Cities of Gastronomy within UCCN and could be applied to cities that have long-standing gastronomic identities and/or intentions to join one or more global or regional gastronomic networks to optimize their gastronomic resources. 
Furthermore, the research suggests that sustainability and creativity have been embedded in core dimensions to achieve gastronomic development, which goes beyond the scope of the Cities of Gastronomy as well as UCCN. The findings of this research will also provide practical implications for gastronomy tourism. Firstly, for those Cities of Gastronomy that have not submitted their monitoring reports, the findings have offered insights about formulating the monitoring report. Secondly, for newly designated Cities of Gastronomy and cities with gastronomic identities, the findings have demonstrated exemplary practices to integrate sustainability and creativity into gastronomic practices at various levels. Thirdly, for cities with gastronomic identities, the findings have illustrated the networking benefits of joining UCCN to facilitate international cooperation. Lastly, the findings have also offered directions for cities that want to revive their gastronomy tourism in a post-COVID-world and/or incorporate gastronomy resources into their long-term development plan.

In addition to offering significant contributions and practical implications, this research also suffers from limitations. Firstly, not all existing Cities of Gastronomy within UCCN have submitted their monitoring reports. So future studies could further look into these gastronomic initiatives when more monitoring reports become available. Secondly, among the available monitoring reports of these member cities, the one submitted by Popayán was written in French, which was excluded from this research. So researchers who are fluent in both English and French could incorporate monitoring reports in both languages into future studies. Thirdly, this research only looked at the monitoring reports submitted for the first round. Since member cities within UCCN need to submit monitoring reports at regular intervals.

So future studies could compare the first and second monitoring reports submitted by the same member cities or holistically look into the second monitoring reports submitted by member cities. Lastly, all the monitoring reports employed in this research were submitted before the COVID-19 pandemic, so this research cannot incorporate the impacts exerted by the global pandemic and how these cities creatively develop their existing gastronomic resources to minimize such impacts, which paves the way for future studies.

Besides the theoretical and practical implications, this research also suffers from the following limitations. Firstly, the empirical data only covered a short period before the start of the Phuket Sandbox Scheme, so future studies could collect more data that cover a longer period for analysis. Secondly, the online comments were not made by actual visitors who entered Phuket under the Sandbox Scheme since the scheme was just initiated, so future studies could either use qualitative or quantitative methods to collect data from international tourists that actually participated in the Phuket Sandbox Scheme.

\section{REFERENCES}

Alimohammadirokni, M., Emadlou, A., \& Yuan, J.J. (2021). The strategic resources of a gastronomy creative city-the case of San Antonio, Texas. Journal of Gastronomy and Tourism, 5(4), 237-252. https://doi.org/10.3727/216929721X16105303036599

Basil, M., \& Basil, D.Z. (2016). Reflections on ultra-fine dining experiences. In Memorable Customer Experiences: A Research Anthology, 155-168, Gower Publishing, Surrey, UK.

Boyne, S., Hall, D., \& Williams, F. (2003). Policy, support and promotion for food related tourism initiatives: a marketing approach to regional development. Journal of Travel and Tourism Marketing, 14(3/4), 131-154. https://doi.org/10.1300/J073v14n03_08

Braun, V., \& Clarke, V. (2006). Using thematic analysis in psychology. Qualitative Research in Psychology, 3(2), 77-101. https://doi.org/10.1191/1478088706qp063oa

Chaney, S., \& Ryan, C. (2012). Analyzing the evolution of Singapore's World Gourmet Summit: An example of gastronomic tourism. International Journal of Hospitality Management, 31(2), 309-318. https://doi.org/10.1016/j.ijhm.2011.04.002

Chang, R.C., \& Mak, A.H. (2018). Understanding gastronomic image from tourists' perspective: A repertory grid approach. Tourism Management, 68, 89-100. https://doi.org/10.1016/j.tourman.2018.03.004

Harrington, R.J. (2005). Defining gastronomic identity: The impact of environment and culture on prevailing components, texture and flavors in wine and food. Journal of Culinary Science \& Technology, 4(2-3), 129-152. https://doi.org/10.1300/J385v04n02_10

Henderson, J.C. (2009). Food tourism reviewed. British Food Journal, 111(4), 317-326. https://doi.org/10.1108/00070700910951470

Hjalager, A.M. (2002). A typology of gastronomy tourism. In Tourism and Gastronomy, 21-35, Routledge, London, UK.

Horng, J.S., \& Tsai, C.T.S. (2010). Government websites for promoting East Asian culinary tourism: A cross-national analysis. Tourism Management, 31(1), 74-85. 10.1016/j.tourman.2009.01.009

Hsieh, A.T., \& Chang, J. (2006). Shopping and tourist night markets in Taiwan. Tourism Management, 27(1), 138-145. https://doi.org/10.1016/j.tourman.2004.06.017

Hsieh, H.F., \& Shannon, S.E. (2005). Three approaches to qualitative content analysis. Qualitative Health Research, 15(9), 1277-1288. https://doi.org/10.1177/1049732305276687

Karsavuran, Z., \& Dirlik, O. (2019). Gastronomy as a tourism resource: the case of Gaziantep. In 4th International Tourism Congress, Eskisehir, Turkey, 86-94.

Khoo, S.L., \& Badarulzaman, N. (2014). Factors determining George Town as a city of gastronomy. Tourism Planning \& Development, 11(4), 371-386. https://doi.org/10.1080/21568316.2013.874365

Kivela, J., \& Crotts, J.C. (2005). Gastronomy tourism: A meaningful travel market segment. Journal of Culinary Science \& Technology, 4(2-3), 39-55. https://doi.org/10.1300/J385v04n02_03

Kozinets, R.V. (2010). Netnography: Doing ethnographic research online, Sage, London, UK.

Lee, K.H., \& Scott, N. (2015). Food tourism reviewed using the paradigm funnel approach. Journal of Culinary Science \& Technology, 13(2), 95-115. https://doi.org/10.1080/15428052.2014.952480

Lin, Y.C., Pearson, T.E., \& Cai, L.A. (2011). Food as a form of destination identity: A tourism destination brand perspective. Tourism and Hospitality Research, 11(1), 30-48. https://doi.org/10.1057/thr.2010.22

Mak, A.H., Lumbers, M., \& Eves, A. (2012). Globalization and food consumption in tourism. Annals of Tourism Research, 39(1), 171196. https://doi.org/10.1016/j.annals.2011.05.010

Mohamed, M.E., Hewedi, M., Lehto, X., \& Maayouf, M. (2019). Marketing local food and cuisine culture online: a case study of DMO's websites in Egypt. International Journal of Tourism Cities, 6(4), 1045-1068. https://doi.org/10.1108/IJTC-05-2019-0067 
Nelson, V. (2015). Place reputation: representing Houston, Texas as a creative destination through culinary culture. Tourism Geographies, 17(2), 192-207. https://doi.org/10.1080/14616688.2014.986751

Park, E., Kim, S., \& Yeoman, I. (2019). Eating in Asia: Understanding food tourism and its perspectives in Asia. In Food Tourism in Asia, 3-13, Springer, Singapore.

Pearson, D., \& Pearson, T. (2017). Branding food culture: UNESCO creative cities of gastronomy. Journal of Food Products Marketing, 23(3), 342-355. https://doi.org/10.1080/10454446.2014.1000441

Richards, G.W. (2002). Gastronomy: An essential ingredient in tourism production and consumption? In Tourism and Gastronomy, 220, Routledge, London, UK.

Riza, M., Doratli, N., \& Fasli, M. (2012). City branding and identity. Procedia-Social and Behavioral Sciences, 35, $293-300$. https://doi.org/10.1016/j.sbspro.2012.02.091

Rosi, M. (2014). Branding or sharing? The dialectics of labeling and cooperation in the UNESCO Creative Cities Network. City, Culture and Society, 5(2), 107-110. https://doi.org/10.1016/J.CCS.2014.05.002

Sandelowski, M. (2000). Whatever happened to qualitative description? Research in Nursing \& Health, 23(4), 334-340. https://doi.org/10.1002/1098-240x(200008)23:4<334::aid-nur9>3.0.co;2-g.

Sangkaew, N., \& Zhu, H. (2020). Understanding tourists' experiences at local markets in Phuket: An analysis of TripAdvisor reviews. Journal of Quality Assurance in Hospitality \& Tourism, 1-26. https://doi.org/10.1080/1528008X.2020.1848747

Seyitoğlu, F., \& Ivanov, S. (2020). A conceptual study of the strategic role of gastronomy in tourism destinations. International Journal of Gastronomy and Food Science, 21, 100230. https://doi.org/10.31235/osf.io/e9za6

Smith, S.L., \& Xiao, H. (2008). Culinary tourism supply chains: A preliminary examination. Journal of Travel Research, 46(3), 289299. https://doi.org/10.1177/0047287506303981

Walters, T. (2016). Using thematic analysis in tourism research. Tourism Analysis, 21(1), 107-116. https://doi.org/10.3727/108 354216 X14537459509017

Xiaomin, C. (2017). "City of Gastronomy" of UNESCO Creative Cities Network: From international criteria to local practice. Social Systems Studies, 55-67. http://www.ritsumei.ac.jp/acd/re/ssrc/result/memoirs/tokusyuugou201707/tokusyuugou201707-08.pdf.

Xie, P.F. (2021). Tourism promotion through the UNESCO Creative City of Gastronomy. Journal of Gastronomy and Tourism, 5(4), 195-206. https://doi.org/10.3727/216929721X16105303036553

Yılmaz, G., Kilıçarslan, D., \& Caber, M. (2020). How does a destination's food image serve the common targets of the UNESCO creative cities network? International Journal of Tourism Cities, 6(4), 785-812. https://doi.org/10.1108/IJTC-07-2019-0115

*** UNESCO Creative Cities Network [UCCN]. (n.d.a). About us. Retrieved from https://en.unesco.org/creative-cities/content/about-us.

*** UNESCO Creative Cities Network [UCCN]. (n.d.b.). Reporting and monitoring. Retrieved from https://en.unesco.org/creativecities/content/reporting-monitoring.

*** UNESCO Creative Cities Network [UCCN]. (2016). The Creative Cities Network: A global platform for local endeavor. Retrieved from http://www.unesco.org/new/fileadmin/MULTIMEDIA/HQ/CLT/pdf/Creative_cities_brochure_en.pdf.

*** UNESCO Creative Cities Network [UCCN]. (2016). The Creative Cities Network: A global platform for local endeavor. Retrieved from http://www.unesco.org/new/fileadmin/MULTIMEDIA/HQ/CLT/pdf/Creative_cities_brochure_en.pdf.

*** UNESCO Creative Cities Network [UCCN]. (2021, April). Guidelines for the membership monitoring report. Retrieved from https://en.unesco.org/creative-cities/sites/default/files/membership_monitoring_reporting_guidelines_2021.pdf.

*** UNWTO. (2017). Second global report on gastronomy tourism. Madrid: UNWTO.

Article history: Received: 02.07.2021 Revised: 22.11.2021 Accepted: 14.12.2021 Available online: 31.12 .2021 